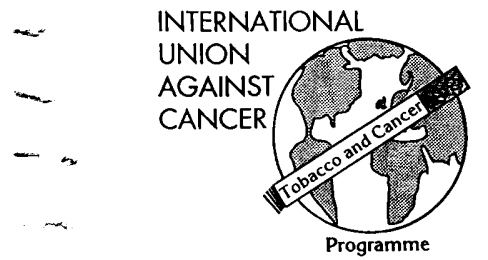

$-$

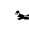

$-5$

\&

*

$\therefore$

\section{UICC regional tobacco control efforts in Latin America}

\section{Pinillos Ashton}

Latin America is an extensive territory which comprises 32 countries and a total population of around 500 million.

In the 1970s, a number of individuals in the region initiated tobacco control activities and as a result, important local and/or national legislation was enacted in several countries.

In the 1980 s, the UICC in cooperation with other agencies, identified national tobacco control leaders, provided training in their countries, and stimulated them to establish National Committees. That led to the creation in 1985 of a Latin American Coordinating Committee on Smoking Control (CLACCTA). At the beginning, five countries met; now 22 nations are represented. The group meets annually with the support and sponsorship of UICC. Through CLACCTA, UICC is very active in the region. AMALTA, the Association of Latin American Women against Tobacco, is also represented within CLACCTA.

It is impossible to speak about each and every one of the National Chairmen, but I can say very briefly, as a means of showing the group's leadership and political influence, that two have become Ministers of Health of their countries (Peru and Venezuela), one a Vice Minister of Health (Dominican Republic), and many are or have been directors of cancer institutes in their countries.

Most of the National Chairmen are medical doctors and many are involved in university education. A good example is Dr José Rosemberg (Brazil), who is Professor of Pneumology of the Pontificia Universidad de Sao Paulo, Brazil, and technical advisor to the Ministry of Health. He has published many scientific books and articles and is without doubt one of the most knowledgeable persons in pathophysiology of tobacco-related diseases. I can also mention Dr Jaime Rios-Dalenz (Bolivia), who has studied and published on the additive negative effect of tobacco and high altitude. $\mathrm{He}$ is also well known in the fight against cancer, as is Dr Helmut Kasdorf (Uruguay).

In Latin America today, most countries have restrictions on tobacco advertising that range from a total ban on $\mathrm{TV}$ and radio advertising to hourly restrictions (only permitted after 8,9 or 10 o'clock at night). There are local, regional or national laws banning smoking in closed public places, and/or banning smoking on domestic flights. There are also tax policies to help fight cancer as well as research in smoking prevalence and attitudes, warnings on cigarette packets, cessation and educational activities in coordination with the Ministries of Education. Most countries organise National Non-Smoking Days, particularly on 31 May, coinciding with the World No-Tobacco Day sponsored by the World Health Organisation. National committees are promoting a very active regional programme: "Latin America Free from Tobacco", directed to three target populations - doctors, teachers, and the media. A quarterly tobacco control bulletin is also published by CLACCTA.

Finally, a strategy and policy for the control of the tobacco epidemic in Latin America was approved at our last meeting in Costa Rica, focusing on primary prevention and the integration of tobacco programmes in public health programmes.

Readers interested in more information on tobacco use, tobacco-related disease, and tobacco control activities in Latin America should consult the following references :

Smoking and health in the Americas. A 1992 report of the Surgeon General, in collaboration with the Pan American Health Organization. Atlanta, Georgia: US Department of Health and Human Services, Centers for Disease Control and Prevention, 1992. (DHHS Publication No (CDC) 928419.)

Tobacco or health: status in the Americas. A report of the Pan American Health Organization. Scientific Publication No 536. Washington, DC: PAHO, 1992. ISBN 9275115362.

The executive summary of the Surgeon General's report was reproduced in Tobacco Control (1992; 1: 150-8). A review of the PAHO report also appeared in Tobacco Control (1993; 2: 61). - ED 